\title{
Detection of pork in meatballs using probe TaqMan Real-time Polymerase Chain Reaction
}

\author{
${ }^{1,2}$ Orbayinah, S., ${ }^{1}$ Hermawan, A., ${ }^{1}$ Sismindari and ${ }^{1,3^{*}}$ Rohman, A. \\ ${ }^{1}$ Faculty of Pharmacy, Gadjah Mada University, Yogyakarta 55281, Indonesia \\ ${ }^{2}$ School of Pharmacy, Faculty of Medical and Health Sciences, Universitas Muhammadiyah Yogyakarta \\ Indonesia. \\ ${ }^{3}$ Institute of Halal Industry and Systems (IHIS), Gadjah Mada University, Yogyakarta 55281, Indonesia.
}

\author{
Article history: \\ Received: 14 June 2019 \\ Received in revised form: 17 \\ February 2020 \\ Accepted: 22 February 2020 \\ Available Online: 19 May \\ 2020
}

\section{Keywords:}

Meatball formulation,

Pork,

Wild boar,

Double quenched TaqMan probe

\section{DOI:}

https://doi.org/10.26656/fr.2017.4(5).227

\begin{abstract}
This study aimed to develop a TaqMan Real-Time Polymerase Chain Reaction method, using a novel primer for detection of pork adulteration in meatballs. The study is important as it described a TaqMan method for product adulteration analysis. TaqMan is known to have a more specific result compared to SYBR green analytical method. Assay in the study combined species-specific primers and TaqMan probes to targeting $153 \mathrm{bp}$ fragment of D-loop mitochondrial region of pork. A specificity test was conducted on fresh tissues of pork, beef, chicken, wild boar, dog, and mouse. Meatballs as samples were prepared from a mixture of pork-beef and wild boar-beef with concentrations as follows: $5 \%, 10 \%, 25 \%, 75 \%, 90 \%$, and $100 \%$. The linearity and sensitivity of the method were performed by measuring the amplification curve from the dilution series, namely 1000 , $200,100,10,5,1$, and $0.5 \mathrm{pg} / \mu \mathrm{L}$ of DNA, extracted from $100 \%$ pork meatballs. A repeatability test was conducted as many as six repetitions on $100 \%$ pork and $100 \%$ wild boar meatballs. This study showed that mitochondrial D-loop species-specific primers and TaqMan probes could identify the DNA of pork and wild boar on the fresh tissues. Additionally, it also resulted in a threshold cycle (Ct) of 17.02 and 17.95 for pork, 22.22 for wild boar, while the negative result for others. The detection limit has shown $5 \mathrm{pg}$ in the meatball formulation. The Relative Standard Deviation (RSD) of repeatability was $1.936 \%$ for pork, while $2.140 \%$ for wild boar. The developed method was also applied to analyzing commercial meatballs. A TaqMan real-time PCR analytical method using specific primer targeting on $153 \mathrm{bp}$ fragment of the D-loop mitochondrial region could be applied as a standard method for identifying pork and wild boar in food samples intended for halal authentication studies.
\end{abstract}

\section{Introduction}

A verification of declared components in commercial meat products does not only help consumers to make a definite purchase decision, but also protect their health, religious belief, and endangered wildlife. Consumers must understand regarding accurate information of the product materials before purchasing. Pork and wild boar are among non-halal meats to be consumed by Muslim communities. A lot of methods have been developed to identify the meats including capillary gel electrophoresis (Hernandes-Chavez, 2011), Enzyme-Linked Immunosorbent Assay (ELISA) (Chen and Hsieh, 2000), chromatographic based techniques (Chou et al., 2007), electronic nose (Nurjuliana et al., 2011), and Fourier Transform Infrared (FTIR) spectroscopy especially in combination with chemometrics, such as principal component analysis and multivariate calibration (Rohman et al., 2011; Xu et al., 2012).

In addition, some methods based on DNA identification including Polymerase Chain Reaction (PCR) using specific primers (Aida et al., 2005; Sahilah et al., 2011), duplex-PCR (Soares et al., 2010), multiplex -PCR (Koppel et al., 2011), real-time-PCR (Eugster et al., 2008; Tjondro and Sismindari, 2012), PCR with electrophoresis, PCR-RFLP (Restriction Fragment Length Polymorphism), real-time PCR with TaqMan probe (Dooley et al., 2004; Kesmen et al., 2009; Ali et al., 2012), real-time PCR molecular beacon, SYBR green real-time PCR were also reported. Among these 
methods, real-time PCR assays combined with speciesspecific primers and TaqMan probes are particularly promising as they provide enhanced specificity and reliability of the assay.

The development of an optimized real-time PCR assay in a background of various food components with shorter amplicon-length is of great value since shorter amplicons are less affected by degradation and they show better recovery of target sequences even in compromised samples (Ali et al., 2012). TaqMan PCR is a type of real-time PCR. It uses a nucleic-acid probe complementary to an internal segment of the targeted DNA. The probe is labeled with two fluorescent moieties. An emission spectrum overlaps the excitation of other spectrums, resulting in "quenching" of the first fluorophore by the second. The probe is present during the PCR and degraded if made via the 5'-nuclease activity of Taq polymerase that is specific for DNA hybridized to a template (TaqMan activity). Degradation of the probe allows two fluorophores to separate, which reduces quenching and increases the intensity of emitted light. Since the assay involves fluorescence measurements able to be performed without opening the PCR tube, the risk of contamination is significantly reduced. Furthermore, no electrophoresis is required, so labor costs are reduced (Sambrook et al., 1989). In this paper, we combined species-specific primers and the TaqMan probes to specifically amplify and detect a short fragment (153-bp) of porcine mitochondrial (mt) D-loop by real-time PCR. A 25-nt TaqMan hydrolysis probe specific for the porcine and endogenous PCR-systems with double quenchers, ZEN probe (Integrated DNA Technologies (IDT), USA) in the middle and Iowa Black at the end, was used to enhance interspecies polymorphism and intra-species specificity. The accuracy and precision of the method were tested in the model experiments, validated in ready-to-eat beef meatballs with spiked pork and wild boar meat and justified in commercially sourced 5 meatballs.

One of the foods to be the main target of adulteration practice is meatball products. Meatballs made with comminuted meat are popular throughout the world. They can be formulated using beef, chicken, pork, and/or fish muscles. However, beef meatballs are very popular and widely found in markets (Rohman et al., 2011). The substitution of beef in meatball formulations with lowervalued meats such as pork frequently takes place to coup up with market competition and also to earn economic benefits. The presence of pork or any of its derivatives in food products is a severe religious concern as they are banned by religious laws of Islam and Judaism (Ali et $a l ., 2012$ ). This study aimed to develop a TaqMan RealTime PCR method for the determination of pork adulteration in meatballs using novel primer intended for halal authentication studies.

\section{Material and methods}

\subsection{Sample collections}

Fresh raw muscle tissues of six meat-providing land animals, namely pork/pig (Sus scrofa), beef/cow (Bos taurus), chicken/hen (Gallus gallus), wild boar (Sus scrofa), dog (Canis lupus familiaris) and mouse (Rattus rattus), were procured from local markets in Yogyakarta. The samples were cut into small pieces and then frozen at $-20^{\circ} \mathrm{C}$ to prevent DNA enzymatic degradation. Commercial meatballs of pork and beef were purchased from local supermarkets in Yogyakarta and Bali.

\subsection{Preparation of meatballs}

Meatballs were prepared by mixing $90 \%$ ground meat with $10 \%$ tapioca starch, cooking salt, garlic, and other spices. The mixture was emulsified and mechanically given to a ball shape. The prepared meatballs were cooked in boiling water for 15 mins to make it suitable for eating.

\subsection{Calibration and validation standards}

In order to prepare a beef meatball calibration, the minced pork was spiked with ground beef to make 0,5 , $10,25,75,90,100 \%$ (wt/wt) pork. The pork was then mixed with $10 \%$ tapioca starch, cooking salt, garlic, and other spices. The mixture was emulsified and mechanically given to a ball shape. Meatballs containing $100 \%$ beef and $100 \%$ pork were also made. All meatballs were cooked in boiling water for 15 mins before the DNA extraction.

\subsection{DNA extraction}

The method of DNA isolation in meats or meatballs was made using Invitrogen ${ }^{\mathrm{TM}}$ PureLink Genomic DNA Mini Kit, made in USA (Cat No. K1820-01; Lot No. 1670947). A-180 $\mu \mathrm{L}$ PureLink ${ }^{\circledR G e n o m i c ~ D i g e s t i o n ~}$ Buffer and $20 \mu \mathrm{L}$ Proteinase $\mathrm{K}$ were added to a $25 \mathrm{mg}$ sample and was incubated in a shaking water bath at 55C for 4 hours. The subsequent steps of the extraction protocol were performed as previously described (Nurjuliana et al., 2011). The purity and content of extracted DNA were determined on the basis of absorbance values, namely A (260/280) and A(260n).

\subsection{Design of primer and probe}

A pair of primers (F: AAA TCG CCC ACT CTTT TCC $\mathrm{C}$ and R: TGT GTT AGG GCC TTT GAC G) targeting $153 \mathrm{bp}$ fragment of the D-loop mitochondrial region of pork was designed using NCBI-Primer BLAST 
software in accordance with the desired criteria. A 25-nt porcine TaqMan probe (6-FAM/AGC CCA TGC/ZEN/ TCA CAC ATA ACT GAG G /3IABkFQ) was designed by tagging 6-carboxyfluoresceine (6-FAM) and 3-Iowa black FQ (3-IABkFQ) at the $5^{\prime}$ and $3^{\prime}$-ends. A second quencher known as ZEN probe (IDT) was introduced at the 10th position of both TaqMan probes to increase the signal-to-noise ratio. The probes and the primers were purchased from the Integrated DNA Technologies (IDT, USA).

\subsection{Real-time PCR analysis}

Amplification of the D-loop mitochondrial was performed in a final volume of $20 \mu \mathrm{L}$ containing $50 \mathrm{ng}$ of extracted DNA, $10 \mu \mathrm{L}$ of SsoFast probe supermix (Bio-Rad, USA), $2 \mu \mathrm{L}(20 \mathrm{mmol})$ of each primer and probe, and $2 \mu \mathrm{L}$ of free nuclease water. The real-time PCR step-cycle program: pre-denaturation at $95^{\circ} \mathrm{C}$ for 5 mins, followed by 30 cycles of denaturation at $95^{\circ} \mathrm{C}$ for $30 \mathrm{~s}$, annealing at $53.3^{\circ} \mathrm{C}$ for $30 \mathrm{~s}$ and extension at $72^{\circ} \mathrm{C}$ for $1 \mathrm{~min}$.

\section{Results and discussion}

This study aimed to develop a TaqMan Real-Time Polymerase Chain Reaction method, using a novel primer for detecting pork adulteration in meatballs. Compared to other studies, which most of them used readily available primers ad probes, this study used new primer and probe design. It used a pair of primers $(\mathrm{F}$ : AAA TCG CCC ACT CTTT TCC C and R: TGT GTT AGG GCC TTT GAC G) targeting 153 bp fragment of the D-loop mitochondrial. For probe, it used a $25-\mathrm{nt}$ porcine TaqMan probe (6-FAM/AGC CCA TGC/ZEN/ TCA CAC ATA ACT GAG G /3IABkFQ). The study is important since it describes a TaqMan method for product adulteration analysis. TaqMan itself is known to have a more specific result compared to SYBR green analytical method.

\subsection{Design of primer}

A $153 \mathrm{bp}$ fragment of the D-loop mitochondrial region of pork was used as a target for real-time PCR. The designed primers and TaqMan probes were verified by NCBI Blast analysis (National Center for Biotechnology Information). A comparatively longer TaqMan probe (25 nucleotides) was used in the present work to ensure better specificity by higher melting temperature. Higher annealing temperature reduces nonspecific amplification, therefore, increasing assay specificity. In order to improve quenching of the longer FAM-labelled probe, ZEN quencher was used at position 10 in addition to 3 '-quencher (Iowa Black).

Temperature optimization for primers attachment was previously done using pork DNAs. A range of temperatures for amplification using the real-time PCR method was from 48 to $54.6^{\circ} \mathrm{C}$ based on the predicted designed primer, while the optimal temperature for primers attachment was at $53.3^{\circ} \mathrm{C}$. At this temperature, the pork DNA could be amplified maximally with the lowest values of $\mathrm{Cq}$ (quantification cycle), and the biggest peak height, as shown in Figure 1.

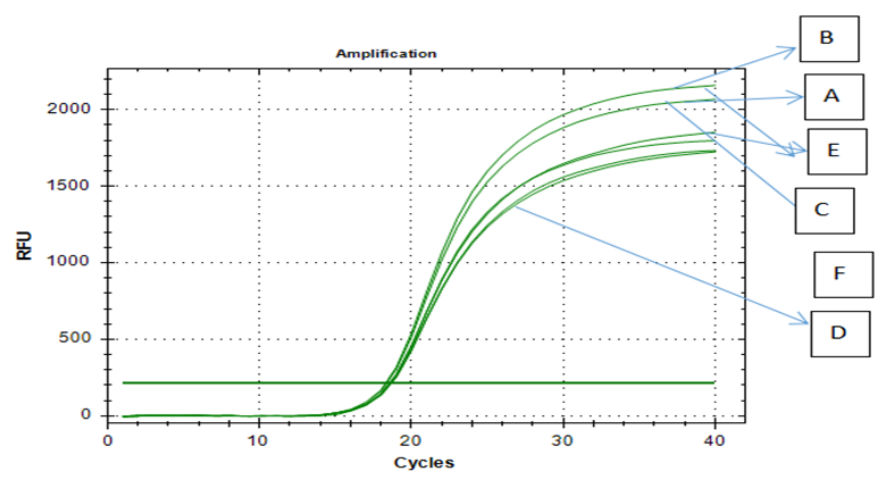

Figure 1. The amplification curve of pig DNA using primer SET 3 at various temperatures, $54.6^{\circ} \mathrm{C}(\mathrm{A}) ; 53.3^{\circ} \mathrm{C}(\mathrm{B}) ; 51.6^{\circ}$ $\mathrm{C}(\mathrm{C}) ; 50.2^{\circ} \mathrm{C}(\mathrm{D}) 49.3(\mathrm{E})$; and $48.8(\mathrm{~F})$.

\subsection{Specificity test}

The specificity of porcine-specific TaqMan real-time PCR assay was conducted using DNA template, isolated from fresh pork and beef (Figure 2a) and pork, wild boar, chicken, dog, and mouse (Figure 2b), and using optimum annealing temperature, $53.3^{\circ} \mathrm{C}$. The result of amplification showed that pork DNA (Figure 2a), pork and wild boar DNA (Figure 2b) could be amplified, while DNA on beef and others were not amplified. It means that designed primers and probes were specific on pork and wild boar DNA.

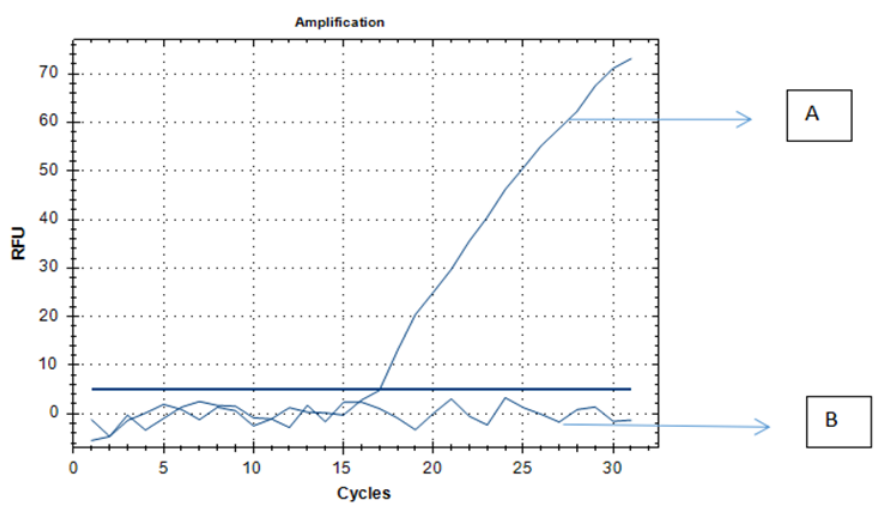

Figure 2 (a). The amplification curve using DNA template extracted from pork (A) and beef (B).

Although the DNA pork was amplified when conducting a Blast only, it turned out that the DNA of wild boar was amplified too in the specification test. This showed that the primers and probes are specific for pork and wild boar DNA. The Resource Ecology Group has compared the DNA of wild boars with domestic pork. A 
total of $10 \%$ of wild boars had DNA fragments from the domestic pork in their genomes. This infiltration by domestic pork genes happened in the past ten years. This can happen because the DNA mixing has taken place on farms where wild boar are being raised for meat consumption. These wild boars are often crossed with domestic pork to increase the brood size and growth rate. Some of them have escaped or have been set free from these farms, allowing them to mate with their wild relatives in the forest. The hybridization proses between wild and domestic relatives might have affected the genetic make-up of a local population. Specificity test with $50 \mathrm{ng}$ DNA of five different species yielded a threshold cycle $(\mathrm{Ct})$ of $17.49 \pm 0.66$ for the pork, 22.22 for the wild boar while the negative results for the others.

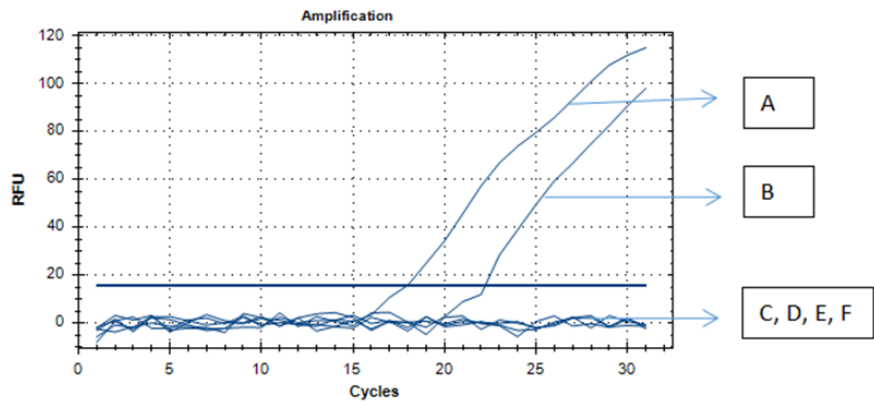

Figure 2 (b). The amplification curve using DNA template, extracted from pig (A), wild boar (B), chicken (C), dog (D), mouse (E) and no template control (NTC) (E).

\subsection{PCR efficiency and detection limit}

In the detection limit test, the pork DNA from 100\% pork meatball was used with the concentrations of 1000 , $200,100,10,5,1,0.5 \mathrm{pg}$, and the DNA of the mixed meatball meat of wild boar-beef with the concentrations of $5 \%, 10 \%, 25 \%, 75 \%, 90 \%$ and $100 \%$. As a result, the mitochondrial D-loop primers can identify the pork DNA up to $5 \mathrm{pg}$ and the mixed meatball meat up to $5 \%$ (Figure $3 a$ and Figure $3 b$ ).

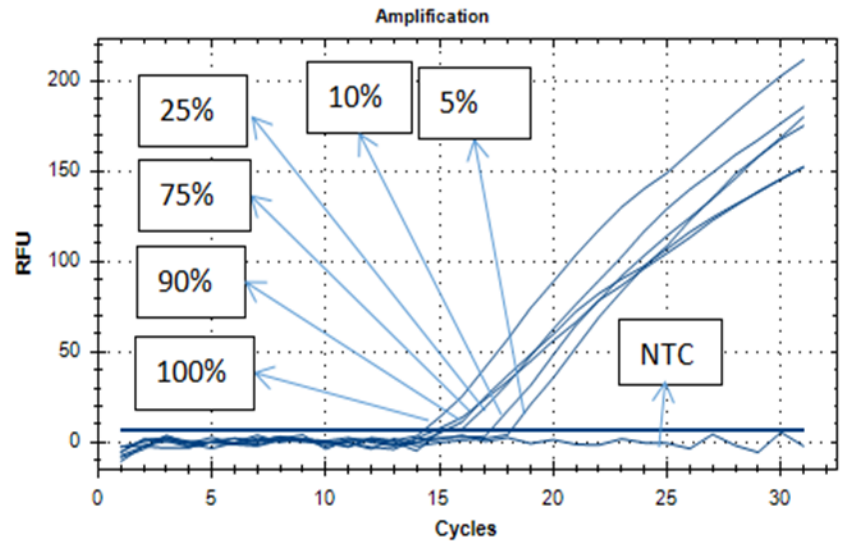

Figure 3(a). The amplification curve of meatball DNA extracted from wild boar meatball DNA with concentrations of $5 \%, 10 \%, 25 \%, 75 \%, 90 \%$ and $100 \%$. NTC = no template control.

Linear regression was obtained with a correlation coefficient $\left(r^{2}=0.940\right)$ and a slope of -4.938 (Figure 4$)$. A calculation of PCR efficiency (E) using the formula, E $=[10(-1 /$ slope $)-1]$, yielded an efficiency of $59.4 \%$ which was within the recommended range $(90-110 \%)$ of real-time PCR efficiency. The repeatability test was done to find out the repeatability of mitochondrial D-loop primers in identifying the pork and the wild boar DNA. The Relative Standard Deviation (RSD) for repeatability was $1.936 \%$ for pork meatballs while $2.140 \%$ for wild boar. The analysis of pork DNA in the sample of beef meatballs in the market did show the amplification, meaning that the meatballs contain pork (Figure 5).

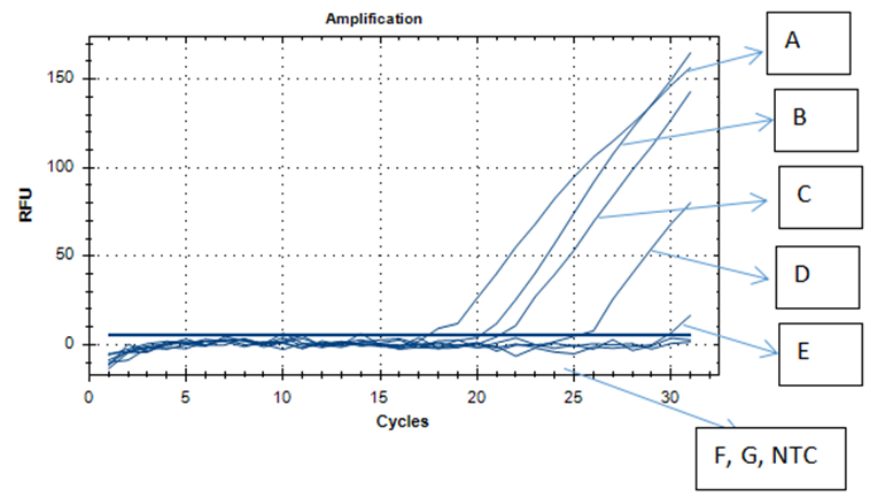

Figure 3(b). The amplification curve of pig DNA extracted from pork meatball $100 \%$ with DNA concentrations of 1000 pg (A), 200 pg (B), 100 pg (C), 10 pg (D), 5 pg (E), 1 pg (F), $0.5 \mathrm{pg}(\mathrm{G})$ and no template control (NTC).

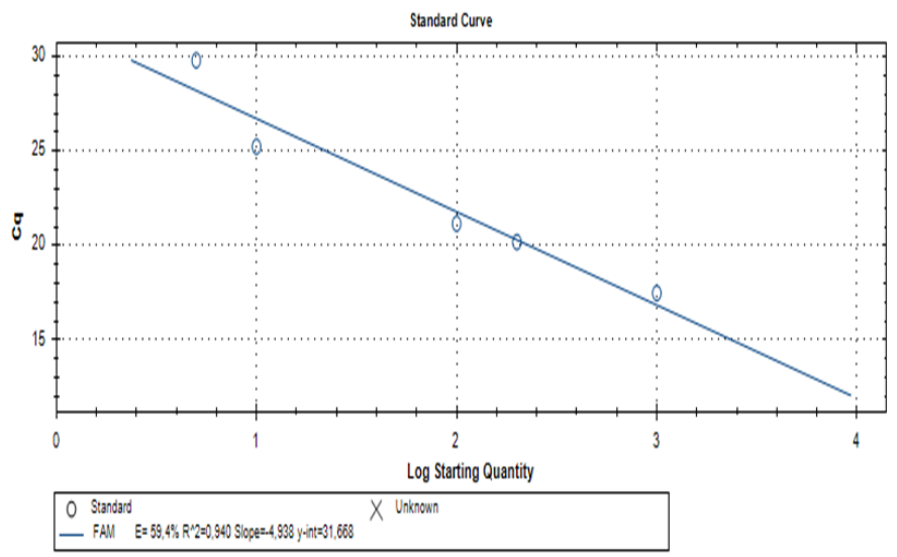

Figure 4. The standard curve of the results of DNA amplification from $100 \%$ pork meatball was used with the concentrations of $1000 \mathrm{pg}, 200 \mathrm{pg}, 100 \mathrm{pg}, 10 \mathrm{pg}, 5 \mathrm{pg}, 1 \mathrm{pg}$, $0.5 \mathrm{pg}$.

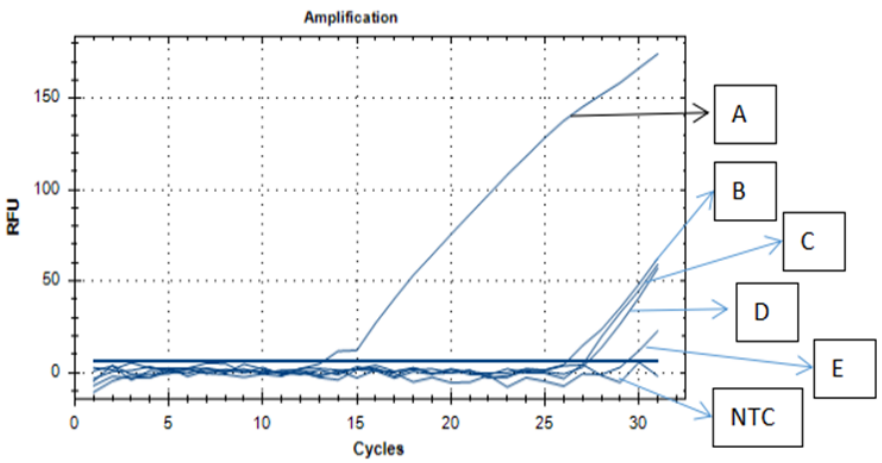

Figure 5. The amplification curves of DNAs extracted from 5 commercial samples (B, C, D, E), no template control (NTC) and positive control (A). 


\section{Conclusion}

A pair of primers (F: AAA TCG CCC ACT CTTT TCC C and R: TGT GTT AGG GCC TTT GAC G) targeting $153 \mathrm{bp}$ fragment of the D-loop mitochondrial and a 25 -nt porcine TaqMan probe (6-FAM/AGC CCA TGC/ZEN/TCA CAC ATA ACT GAG G /3IABkFQ) were specific to be used for identification of pig and wild boar DNA using a Taqman real-time PCR with the optimum annealing temperature was $53.3^{\circ} \mathrm{C}$. The validated real-time PCR using the above primer and probe could be proposed as a standard method for detection of pork and wild boar DNA in commercial samples. However, the limitation of this study was that primes and probes for pork designed in this study also amplified wild boar meat, which was not specific for pork. It means that future study could be designed specifically for pork.

\section{Conflict of interest}

The author declares that there is no conflict of interest

\section{Acknowledgement}

The author thanks the Ministry of research and higher education for financial support during this study through Penelitian Unggulan Perguruan Tinggi 20172018 awarded to Prof. Dr. Sismindari.

\section{References}

Aida, A.A., Che Man, Y.B., Wong, C.M.V.L., Raha, A.R. and Son, R. (2005). Analysis of raw meats and fats of pigs using polymerase chain reaction for halal authentication. Meat Science, 69(1), 47-52. https:// doi.org/10.1016/j.meatsci.2004.06.020

Ali, M.E., Hashim, U., Mustafa, S., Che Man, Y.B., Dhahi, T.S., Kashif, M., Kamal Uddin, M. and Abd Hamid, S.B. (2012). Analysis of pork adulteration in commercial meatballs targeting porcine-specific mitochondrial cytochrome $\mathrm{b}$ gene by TaqMan probe real-time polymerase chain reaction. Meat Science, 91(4), $\quad 454-459 . \quad$ https://doi.org/10.1016/ j.meatsci.2012.02.031

Chen, F.C. and Hsieh, P.Y.H. (2000). Detection of pork in heat-processed meat products by monoclonal antibody-based ELISA. Journal of AOAC International, 83(1), 79-85. https://doi.org/10.1093/ jaoac/83.1.79

Chou, C., Lin, S., Lee, K., Hsu, C., Vickroy, T.W. and Zen, J. (2007). Fast differentiation of meats from fifteen animal species by liquid chromatography with electrochemical detection using cooper nanoparticle plated electrodes. Journal of
Chromatography B, 846(1-2), 230-239. https:// doi.org/10.1016/j.jchromb.2006.09.006

Dooley, J.J., Paine, K.E., Garrett, S.D. and Brown, H.M. (2004). Detection of meat species using TaqMan real -time PCR assays. Meat Science, 68(3), 431-8. https://doi.org/10.1016/j.meatsci.2004.04.010

Eugster, A., Ruf, J., Rentsch, J., Hubne, P. and Koppel, R. (2011). Quantification of beef and pork fraction in sausage by real-time PCR analysis: results of an inter -laboratory trial. European Food Research Technology, 227, 1-7. https://doi.org/10.1007/s00217 $-007-0686-9$

Hernandes-Chavez, J.F., Gonzalez-Cordova, A.F., Rodriguez-Ramirez, R. and Vallejo-Cordoba, B. (2011). Development of a polymerase chain reaction and capillary gel electrophoresis method for the detection of chicken or turkey meat in heat-treated pork meat mixtures. Analitica Chimica Acta, 708(12), 149-154. https://doi.org/10.1016/ j.aca.2011.08.039

Kesmen, Z., Gulluce, A., Sahin, F. and Yetim, H. (2009). Identification of meat species by TaqMan-based real -time PCR assay. Meat Science, 82(4), 444-449. https://doi.org/10.1016/j.meatsci.2009.02.019

Koppel, R., Ruf, J. and Rentsch, J. (2011). Multiplex real -time PCR for the detection and quantification of DNA from beef, pork, horse and sheep. European Food Research Technology, 232, 151-155. https:// doi.org/10.1007/s00217-010-1371-y

Nurjuliana, M., Che Man, Y.B., Mat Hashim, D. and Mohamed, A.K.S. (2011). Rapid identification of pork for halal authentication using the electronic nose and gas chromatography mass spectrometer with headspace analyzer. Meat Science, 88(4), 638844. https://doi.org/10.1016/j.meatsci.2011.02.022

Rohman, A., Sismindari, Erwanto, Y. and Che Man, Y.B. (2011). Analysis of pork adulteration in beef meatball using Fourier transform infrared (FTIR) spectroscopy. Meat Science, 88(1), 91-95. https:// doi.org/10.1016/j.meatsci.2010.12.007

Sahilah, A.M., Norhayati, Y., Norrakiah, A.S., Aminah, A. and Wan Aida, W.M. (2011). Halal authentication of raw meats using PCR amplification of mitochondrial DNA. International Food Research Journal, 18(4), 1489-1491.

Sambrook, J., Fritsch, E.F. and Maniatis, T. (1989). Molecular Cloning: A Laboratory Manual. New York: Cold Spring Harbor Laboratory Press.

Soares, S., Amaral, J.S., Mafra, I. and Oliveira, M.B.P.P. (2010). Quantitative detection of poultry meat adulteration with pork by a duplex PCR assay. Meat Science, 85(3), 531-536. https://doi.org/10.1016/ 
j.meatsci.2010.03.001

Tjondro, F. and Sismindari. (2012). Detection of pork in burger using real-time PCR with LEF primer presented at Proceeding of the 2nd international seminar on halalness and safety food and pharmaceutical product 17-18 Oct 2012. Yogyakarta.

Xu, L., Cai, C.B., Cui, H.F., Ye, Z.H. and Yu, X.P. (2012). Rapid discrimination of pork in halal and non-halal Chinese ham sausages by Fourier Transform Infrared (FTIR) spectroscopy and chemometrics. Meat Science, 92(4), 506-510. https://doi.org/10.1016/j.meatsci.2012.05.019 